\title{
Improved service governance in notary administration system through multi channel access implementation
}

\author{
A. A. Kompiang Oka Sudana, Ni Kadek Giofanni Chandra Devi, I Made Suwija Putra \\ Department of Information Technology, Universitas Udayana, Indonesia
}

\section{Article Info}

Article history:

Received Jan 15, 2020

Revised Feb 29, 2020

Accepted Mar 5, 2020

\section{Keywords:}

Administration system

Multi channel access

Notary

SMS

Telegram

\begin{abstract}
Notary is an official authorized to make an authentic deed regarding all deeds, agreements and stipulations required by a general rule. Activities carried out at the notary office such as recording client data and file data still use traditional systems that tend to be manual. The problem that occurs is the inefficiency in data processing and providing information to clients. Clients have difficulty getting information related to the progress of documents that are being taken care of at the notary's office. The client must take the time to arrive to the notary's office repeatedly to check the progress of the work of the document file. The purpose of this study is to facilitate clients in obtaining information about the progress of the work in progress, and make it easier for employees to process incoming documents by implementing an administrative system. This system was developed with the waterfall system development method and uses the Multi-Channel Access Technology integrated in the website to simplify the process of delivering information and requesting information from clients and to clients with Telegram and SMS Gateway. Clients will come to the office only when there is a notification from the system via Telegram or SMS notifying that the client must come directly to the notary's office, thus leading to an efficient time and avoiding excessive transportation costs. The overall functional system can function properly based on the results of alpha testing. The results of beta testing conducted by distributing the system feasibility test questionnaire to end users, get a percentage of $96 \%$ of users agree the system is feasible to be implemented.
\end{abstract}

This is an open access article under the $\underline{C C B Y-S A}$ license.

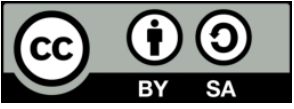

\section{Corresponding Author:}

Ni Kadek Giofanni Chandra Devi,

Department of Information Technology,

Universitas Udayana,

J1. Raya Kampus Unud Jimbaran, Kec. Kuta Sel., Kabupaten Badung, Bali 80361, Indonesia.

Email: giofannidevi@gmail.com

\section{INTRODUCTION}

Recording client data and certificate file data in the Notary's office is still done with traditional systems that tend to be manual. The problem that occurs is the inefficiency in processing data and providing information to clients, because processes like recording client data, incoming certificate file data, and making reports are still done by handwriting on the book. Clients have difficulty getting information related to the progress of the file that is being taken care of at the notary's office. The client must take the time to arrive to the notary's office repeatedly to check the progress of the document file.

This study proposes the application of a notary administration system to solve this problem. Client data and certificate file data entered will be processed so as to produce a certificate registration number that will be provided to the client for use in tracking files. Clients can also receive notifications whenever there is 
a status update of a job from an employee. Similar to previous research which can only be accessed via telegram, clients who do not have supporting devices such as smartphones or laptops cannot access the administration system [1].

Web-based notary administration system and integrated with Multi-Channel Access (MCA) technology to facilitate clients access information related to the work status of files from multiple channels. Notary administration system is designed to make it easy for clients to get information about the status of work files. In addition, this system makes it easy for employees to record and process incoming data files. This system will send a notification message to the client when a job status update occurs on the system, a notification message will be received by the client either through the Telegram application or SMS Gateway. Clients can also request file job status via the Telegram and SMS application by entering the client service code. Therefore, clients do not need to come to the office and contact employees by telephone to find out the status of work files that are running.

Research related to the use of Telegram technology and SMS Gateway, namely research student attendance applications using Telegram Messenger technology. Telegram messenger here serves as a medium for sending information to students' parents regarding their child's attendance at school[1]. The disadvantage of this application is that it only sends information via the Telegram Application, so parents of students who don't have smartphones cannot access it. Research carried out adds an SMS Gateway to facilitate users who do not have a smartphone.

Other research is a student information system integrated with SMS gateway. Students can send messages according to the code provided to get information from the university. The SMS feature integrated with the system will speed up the process of delivering information from the university to students. The weakness of this system is that it only focuses on SMS [2]. In addition to expensive credit fees, people use more data packages in this internet era. Research carried out is to add Telegram technology to the system created to facilitate users who currently have a lot of applications to use messaging services.

Other research is about systems that approve research applied at Educational Institutions. This system is integrated with SMS and Email. Students can receive information quickly and easily related to exam results and grades during studies[3]. The weakness of this system is the system can only do One-Way communication. So the user only receives approval of exam results and grades during the course of study. Research carried out is to create a notary administration system using multi-channel access technology using Telegram and SMS Gateway Applications. The system can make Two-Way communication, where users can request service details by entering the service code, Telegram bot and SMS will reply as requested by the user.

Other research related to the use of SMS gateway technology is regarding the notification system related to school events. This system is integrated with SMS. When the admin enters the event data, information will be disseminated via a GSM modem. This GSM modem will communicate with cellular networks. Furthermore, the information is sent to each cellphone [4]. The weakness of this system is that this system can only do one-way communication. The system will provide notifications regarding school events to students, parents and teachers, whereas research conducted by the system can carry out two-way communication where users can ask for detailed service status. Telegram and SMS bots will provide a reply in the form of information on what stages have been completed and what stages have not been completed. Other research related to file monitoring system, this system allows users to manage documents, as well as the ease of monitoring a document [5].

Research related to the use of SMS gateway technology as a medium for delivering information is an agricultural information system. This system is integrated with SMS gateway and allows farmers to receive notifications related to weather conditions, tips on agricultural cultivation, information related to disaster warnings, and information on plant diseases that might occur. Farmers can also send messages in the form of questions related to agricultural information. The weakness of this system is the focus on the use of SMS [6]. Similar research, namely regarding the SPP payment reminder system and school activity information integrated with SMS Gateway. This system makes it possible to send information in the form of SPP payment bills and school activity information via SMS. Users can also send messages to request certain information according to the format. The weakness of this system is that it only focuses on using SMS Gateway technology. The use of SMS in the internet era like today can be said to have been very rare because of expensive credit fees [7]. Research carried out adds Telegram and SMS Gateway Applications to facilitate clients in monitoring and receiving notifications through both Telegram and SMS Applications. From the results of previous studies and interviews with notary and land registrar parties, a web-based online notary administration information system is integrated with the Telegram application and SMS gateway to facilitate clients in monitoring and receiving notifications.

SMS gateway has two directional characteristics which are very suitable to be used as an SMS center, in terms of its development the SMS center consists of two types, one of which uses the SMPP 
protocol that is connected to the internet network, and the SMS server service that is connected directly to the GSM network [8].

Telegram Application Programming Interface (API) is a set of special rules that can be accessed by other software to implement the API [9]. The Telegram API can also be used to create bots that are used as a medium for sharing information. Information can be obtained by using Telegram Bot by sending messages in the form of requests. The main purpose of using bots is to increase user comfort. The use of Telegram Bot has several benefits because it can save internet data usage, time, and storage, because information can be obtained from bots without opening a website [10]. Website is a collection of pages consisting of several pages containing digital information in the form of images, text and animations that are provided via the internet so that they can be accessed from all over the world. The website consists of several elements, namely web design, web hosting, programming languages, domain names, and file transfer protocols. Access requests made by users are responded to by the web application, then displayed via a display on the web browser used. Website services are used as facilities provided to provide services in the form of information to other systems, so other systems can interact with the system through services provided by systems that provide website services [11].

\section{RESEARCH METHOD}

The system development methodology used in this research is the waterfall method. The waterfall model is a linear sequential flow where progress is seen flowing downward like a waterfall through the software implementation phase. This model means that each phase in the development process starts only if the previous phase is completed [12]. The waterfall model defines several sequential phases that must be completed one by one and moves to the next phase only when the previous phase has been done or completed [13]. The waterfall model is recursive because each phase can be repeated endlessly until it is perfect.

\subsection{Analysis}

The analysis phase is the stage of defining the functions, behavior, and the specifications of user's needs to understand the business processes in the notary administration system. Data collection is done through observations and interviews to get the specifications of user needs. The following are the results that can be elaborated from observations and interviews conducted related to the specifications of functional and non-functional requirements.

\subsubsection{Identification of functional requirements}

At this stage the main thing that needs to be done is to identify needs. The requirements referred to are the determination of how to use the system, the data that must be entered into the system process, and the output requirements of the system process [14].

a. Input requirements

The following are the input requirements needed to fulfill the system implementation:

- $\quad$ Data such as: username and password needed to login system.

- User Data which includes: id user, username, password, and access privilege status.

- Master Data which includes: client data, service type data, phase data, form data, notary data, and requirements data.

- $\quad$ System Configuration Data which includes: phase type service settings, and setting the form on the type of service.

b. Process requirements

Analysis of process requirements in the developed system consists of:

(1) Configuration process

The process of configuration data can only be done by the admin. The process includes: setting the type of service phase, and setting the type of service. Data processing on the system requires setting the service type phase and setting the service type form first so that the system processes the input data according to the selected service type.

(2) Entering client data process

The process of entering client data includes: client number, NIK, name, address, NPWP, gender, mobile number, marital status, occupation, and telegram ID.

(3) Entering master data process

The process of entering parameter data includes: entering service type data, form data, phase data, condition data, and notary data.

(4) Transaction process

Improved service governance in notary administration system through ... (A. A. Kompiang Oka Sudana) 
The administrative system transaction process at this notary office includes: registration of new clients, making requests for types of services, and processing data files.

(5) Notification process

The notification process includes: notifications related to job status information via the Telegram and SMS Application.

c. Output requirements

Output requirements include: file data reports for each type of service entered, file job status information sent to the client via Telegram and SMS applications.

\subsection{Design}

The design phase is a multi-step process that focuses on software design, which includes data structures, software architecture, interface design, and coding procedures.

\subsubsection{Designing admin access right}

Admin has full control access rights to the system. Admin is one of the employees assigned to hold the system. Admin access rights have the following authority: processing client data, processing parameter data consisting of (service type data, form data, phase data, condition data, and notary data), processing request data, updating progress, viewing and printing reports, setting the service type phase, setting the service type form.

\subsubsection{Data flow diagram}

DFDs are mostly used by system designers to simplify system design [15]. Overview Diagram of the notary administration system can be seen in Figure 1.

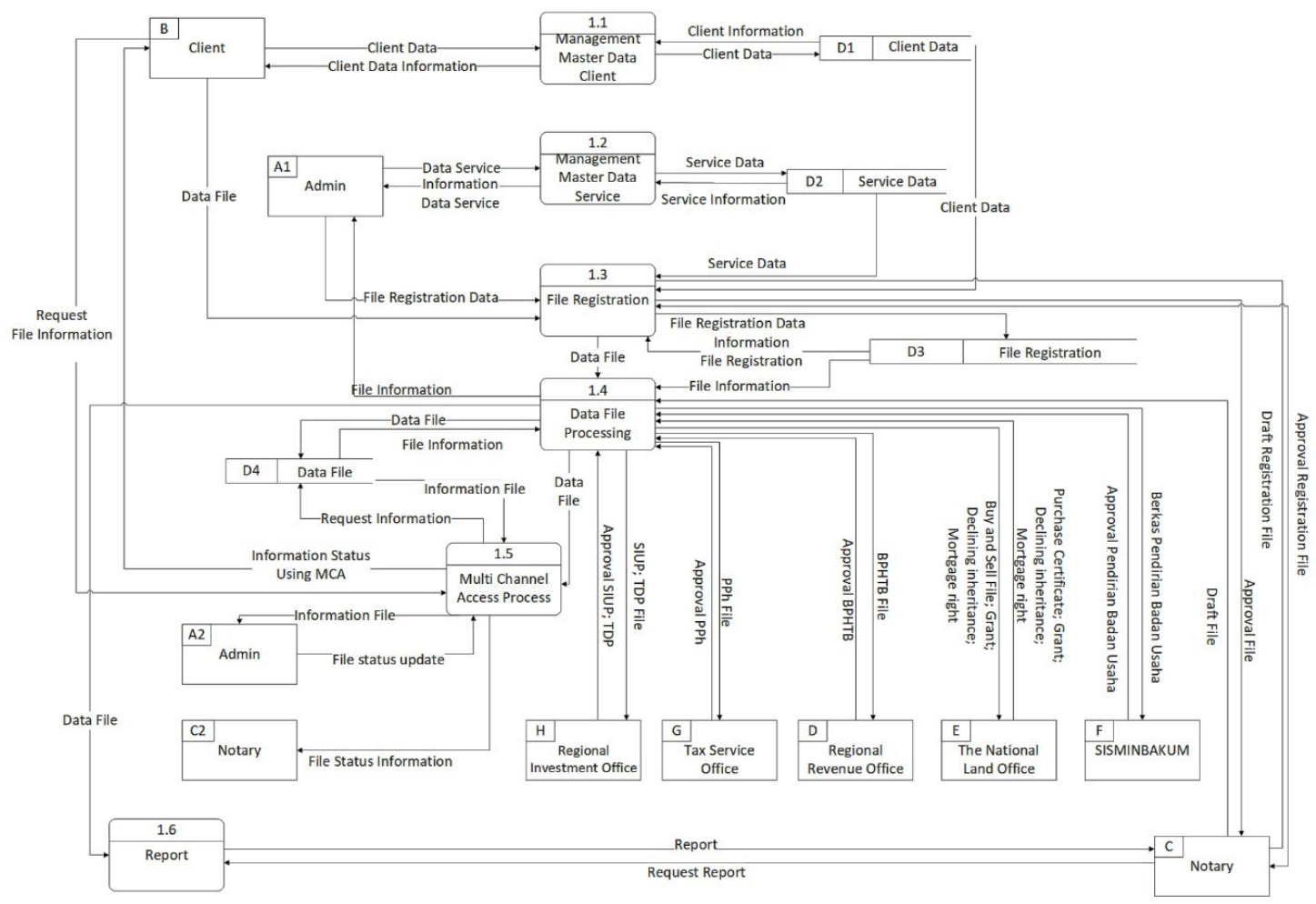

Figure 1. Overview diagram

Figure 1 shows an overview of the notary administration system diagram. This diagram overview has six processes, which consist of the master data management process, the file registration process, the file data processing process, the status notification process, and the reporting process. Process flow for the master data management process, i.e. employees will input client data and service data, the data will be saved to 
the database. The next process is the file registration process. The file registration process starts from the employee inputting the file data provided by the client. The file registration data will be a draft file registration that will be sent to the notary for approval, after receiving the approval, the file registration data will go into the file data processing.

The process that occurs in processing data files that is data files that have been approved will be processed according to the type of service selected by the client. Clients who submit documents for sale and purchase, the file after being processed at the notary's office will be sent to Regional Revenue Office and Tax Service Office for tax payment. After payment of tax, the file will be sent to the The National Land Office for making certificates. Clients who submit a business establishment file, the file will be sent to SISMINBAKUM for registration, and to the Regional Investment Office Entity for the making of SIUP (business permit) and TDP.

The file processing information will go to the employee entity. The employee will update the file status. Then the file information will be sent to the client entity and notary entity through the Telegram and SMS application. Clients can also retrieve file job status information via the Telegram and SMS application. The final process, namely reporting, overall administrative data that occurs in the administrative information system will be sent to the notary

\subsubsection{Architecture system}

The system architecture of the notary administration system is explained in the following figure. Figure 2 shows the architecture of the administration system. The process that occurs is that the client comes to the notary's office to submit the registration file. The employee will enter the service request data in the system. Then the client will get a registration number as registration data. The registration number can be used by clients to request status information for work files that are currently running via SMS or Telegram application. For the clients who request information via SMS, their messages will be forwarded to the android SMS gateway server and then forwarded to the server. When a client requests information via Telegram, the message will be sent directly to the server. File data will be displayed on the website to be accessed by employees, when one phase of service has been completed, the employee will update progress, when the update process occurs, it will trigger the server to send a notification to the client in the form of information on the status of work files that are running or have been completed. Messages will be sent via SMS if the client request via SMS, and via Telegram if the client requests via the Telegram application.
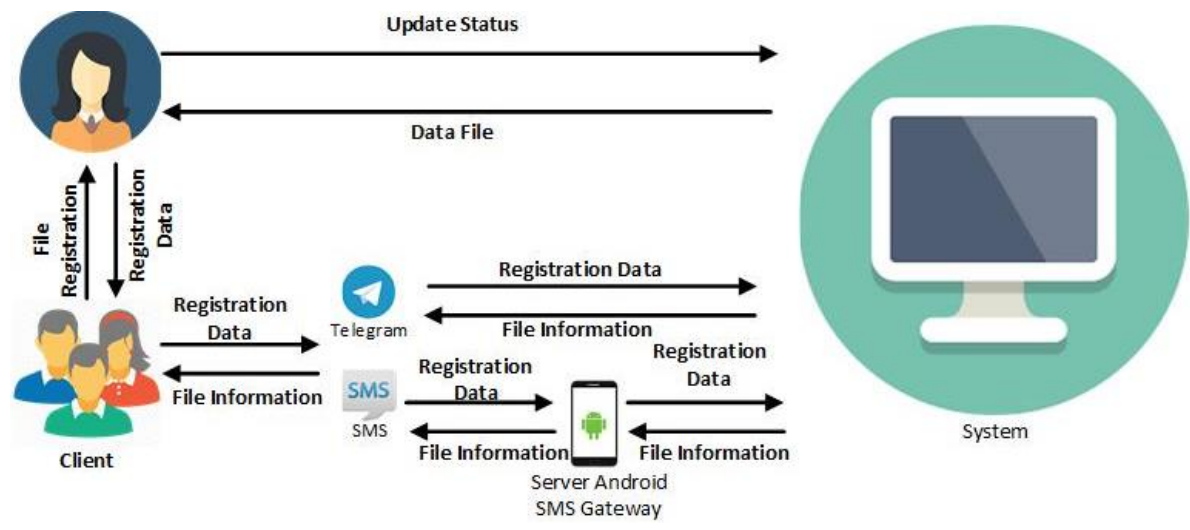

Figure 2. System Architecture

\subsection{Implementation}

Figure 3 A pseudocode line from the notary administration system that functions to store service request data. Figure 3. explains the pseudocode for the administration system of the notary service. The first system workflow is making requests from clients by employees. The employee will enter the client id and type of service, then the data will be stored in the database. To see client requests, the system will check according to the request id, if data is available then the data will be displayed immediately. Data updating is done when one phase has been fulfilled or has been completed, when the employee clicks the update progress button, the system will immediately send notification of file status information to the client.

Figure 4 describes the pseudocode for sending notifications from the administration system. This send notification runs when there is a progress update from the system. The system will send notifications according to the telegram id and telephone number of the client.

Improved service governance in notary administration system through ... (A. A. Kompiang Oka Sudana) 


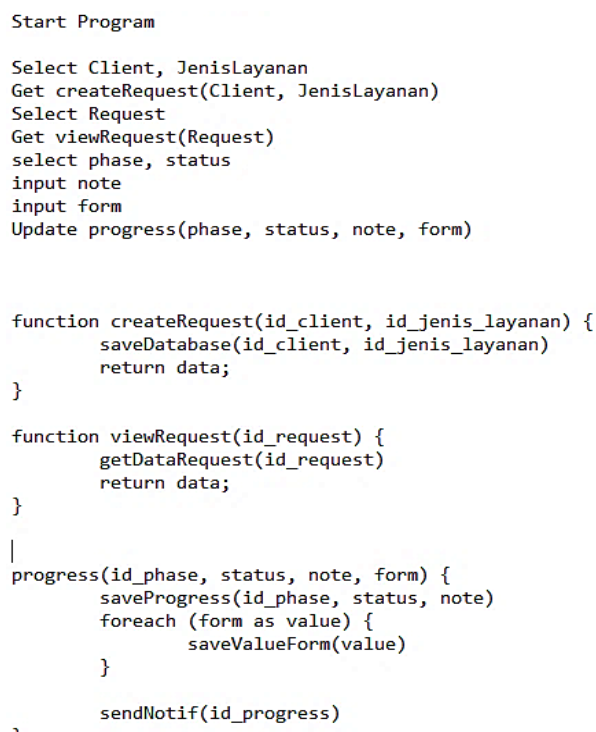

Figure 3. Pseudocode create request

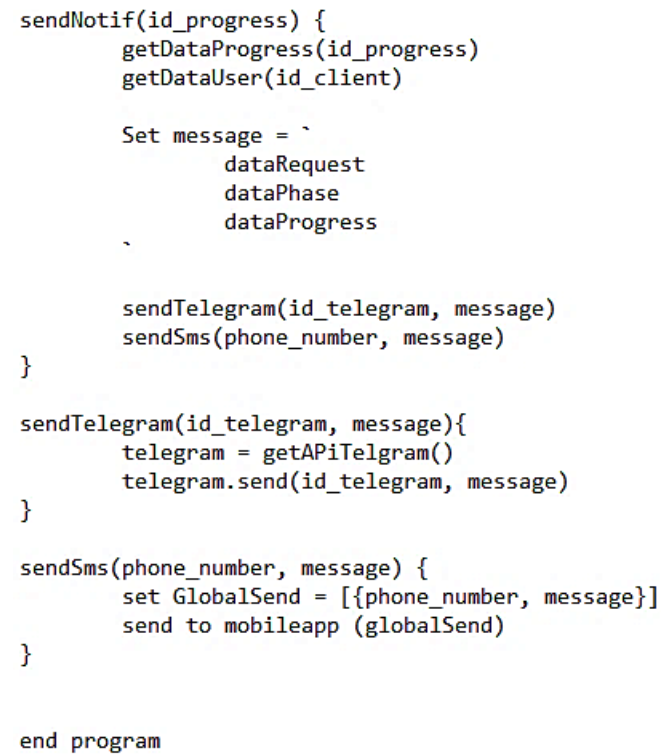

Figure 4. Pseudocode send notification

\subsection{Testing}

The tests are carried out using the alpha testing and beta testing approach. Alpha testing is the first stage of testing and will be carried out between teams [16], alpha testing is done to test system functionality as shown in Table 1.

Table 1. Testing planning

\begin{tabular}{|c|c|c|c|c|c|}
\hline No & Access & Test class & Test item & Testing type & Status \\
\hline 1 & Admin & Login & Verification & Blackbox & Valid \\
\hline 2 & Admin & Master data client & $\begin{array}{c}\text { Add data } \\
\text { Update data } \\
\text { Delete data }\end{array}$ & Blackbox & Valid \\
\hline 3 & Admin & Master data user & $\begin{array}{l}\text { Add data } \\
\text { Update data } \\
\text { Delete data }\end{array}$ & Blackbox & Valid \\
\hline 4 & Admin & Master data jenis pelayanan & $\begin{array}{c}\text { Add data } \\
\text { Update data } \\
\text { Delete data }\end{array}$ & Blackbox & Valid \\
\hline 5 & Admin & Master data phase & $\begin{array}{c}\text { Add data } \\
\text { Update data } \\
\text { Delete data }\end{array}$ & Blackbox & Valid \\
\hline 6 & Admin & Master data syarat & $\begin{array}{c}\text { Add data } \\
\text { Update data } \\
\text { Delete data }\end{array}$ & Blackbox & Valid \\
\hline 7 & Admin & Master data form & $\begin{array}{c}\text { Add data } \\
\text { Update data } \\
\text { Delete data }\end{array}$ & Blackbox & Valid \\
\hline 8 & Admin & Master data notaris & $\begin{array}{c}\text { Add data } \\
\text { Update data } \\
\text { Delete data }\end{array}$ & Blackbox & Valid \\
\hline
\end{tabular}

\section{RESULTS AND DISCUSSION}

Tests were carried out using two methods, namely black box testing (alpha testing) and Likert scale analysis (beta testing). Black box testing is testing the functionality of the system being developed [17]. Likert scale analysis is an analysis in which respondents are asked to evaluate by giving quantitative values to subjects or objects, with the level of agreement / disagreement [18]. For calculations with Likert scale analysis, the equation can be used as in (1),

$$
\text { Index Formula } \%=\frac{\text { Total Score }}{Y} \times 100 \%
$$


Total score shows the number of respondents multiplied by the weight of Likert value and $\mathrm{Y}$ is the total number of respondents multiplied by the highest Likert score. Questionnaire table as shown in Table 2.

Table 2. Questionnaire table

\begin{tabular}{|c|c|c|c|c|c|c|}
\hline \multirow{2}{*}{ No } & \multirow{2}{*}{ Aspects } & \multicolumn{5}{|c|}{ Assesment } \\
\hline & & SA & A & $\mathrm{N}$ & $\mathrm{D}$ & SD \\
\hline 1 & Are all feature in accordance with administrative requirement? & 5 & & & & \\
\hline 2 & Is the feature running well? & 3 & 2 & & & \\
\hline 3 & Is the Telegram and SMS Gateway on the application used is running well? & 4 & 1 & & & \\
\hline 4 & $\begin{array}{l}\text { Does the Telegram and SMS Gateway in the application provide information } \\
\text { according to client needs? }\end{array}$ & 3 & 2 & & & \\
\hline 5 & $\begin{array}{l}\text { Notary administration system is appropriate to be used to assist the } \\
\text { administration process in a notary's office }\end{array}$ & 5 & & & & \\
\hline & Total & 20 & 5 & & & \\
\hline
\end{tabular}

Table 3 shows the value of the number of respondents. There are 4 people with 5 questions. The highest number of values is 5 , and the value of the trade is 1 . From the calculation of the questionnaire, the percentage is as follows:

a. $\quad$ Total score $=($ highest total voter $\mathrm{x}$ score $)+($ lowest total $\mathrm{x}$ score $)$

Total score $=(20 \times 5)+(5 \times 4)$

Total score $=120$

b. Highest score $=$ (highest score $\mathrm{x}$ number of questions $\mathrm{x}$ number of respondents)

$=(5 \times 5 \times 5)$

Highest score $=125$

c. Index Formula $\%=\frac{\text { total score }}{\text { highest score }} \times 100 \%$

$=\left(\frac{120}{125}\right) \times 100 \%$

$=96 \%$

Table 3. Percentage value table

\begin{tabular}{cc}
\hline The answer & Explanation \\
\hline $0 \%-19,99 \%$ & Strongly Disagree \\
$20 \%-39,99 \%$ & Disagree \\
$40 \%-59,99 \%$ & Neutral/ Neither Agree nor Disagree \\
$60 \%-79,99 \%$ & Agree \\
$80 \%-100 \%$ & Strongly Agree \\
\hline
\end{tabular}

Based on the results of the questionnaire it can be concluded that the Notary Administration System has been accepted and implemented at the notary's office.

\subsection{System user characteristic}

This notary office administration system is used specifically by employees and officials who are notaries. The characteristics of the notary office administration system users are as follows. Users who act as admin of the system manager are on average educated from high school to undergraduate, where knowledge of technology related to social media, information technology, and instant messaging is customary and even has become the user's needs [19]. Further user characteristics, namely based on customer needs. The needs of customers who will use this system, namely customers who take care of documents at the notary's office want that any information related to the progress of the document work is obtained easily without having to come directly to the notary's office. The current problem in the notary's office is that it does not yet have a system that is able to accommodate this. So, the client must spend many times to come directly to the notary's office in order to know the progress of the documents being taken care of. This system is designed for users who have behaviours or habits that often carry out process activities in the land sector (such as the buying and selling process), in the area of agreements in terms of managing power, and in the area of establishing business entities (such as the establishment of a company).

The choice of Telegram instant messaging for the media of providing information and communication is because the Telegram application is one of the instant messaging platforms based on open source. From the start of Telegram until now, this application has gained popularity status and has become a widely used instant messaging application. The Telegram application also provides a Bot feature that can

Improved service governance in notary administration system through ... (A. A. Kompiang Oka Sudana) 
answer commands automatically with answers that have been formatted[19]. The choice of SMS gateway technology as a medium for providing information and communication is to accommodate users who do not have a smartphone or laptop, so that users can still obtain and request information related to the progress of the document being managed.

\subsection{Client registration process}

This notary office administration system is web-based and already integrated with the Telegram Application and SMS gateway. The registration data input process can be done in two ways namely by the client directly through the website or the admin of the system manager registering the client data through the system. The following is the process of data input by the client through the website.

Figure 5 is the first step page display that must be filled by the client. The first step is choosing the type of service. After the client chooses the type of service, the client will proceed to the next step, which is to fill in the personal data.

Figure 6 is a form display filled with personal client information. The client must complete the data related to personal information before proceeding to the next step.

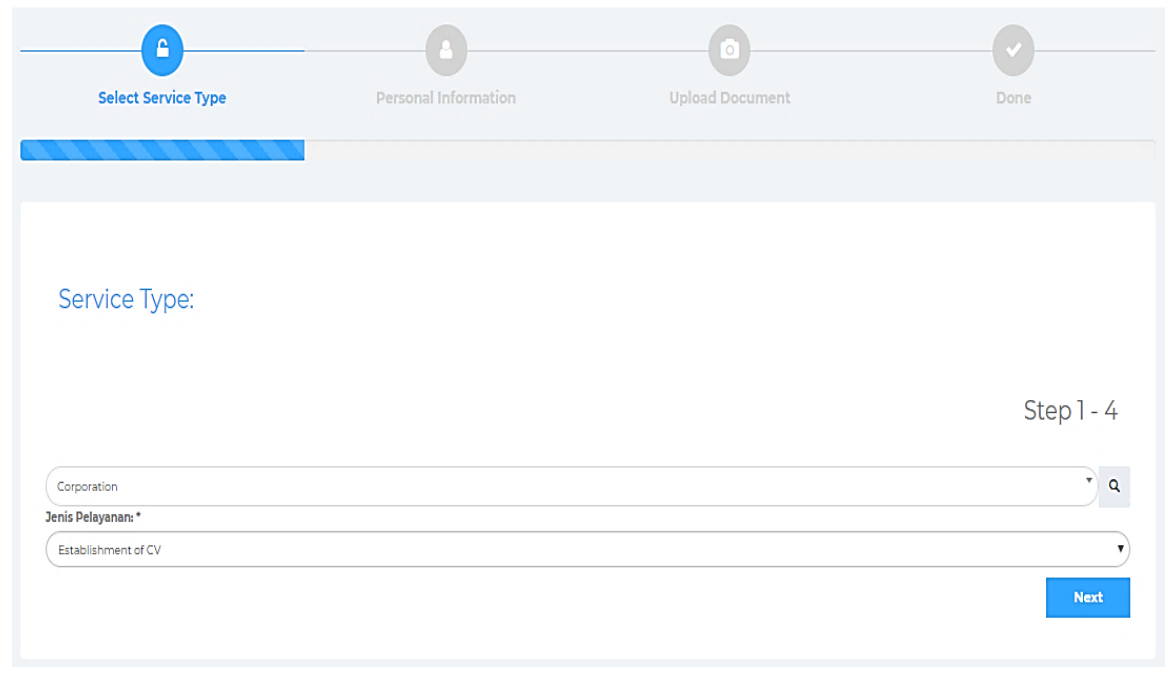

Figure 5. Input type of services

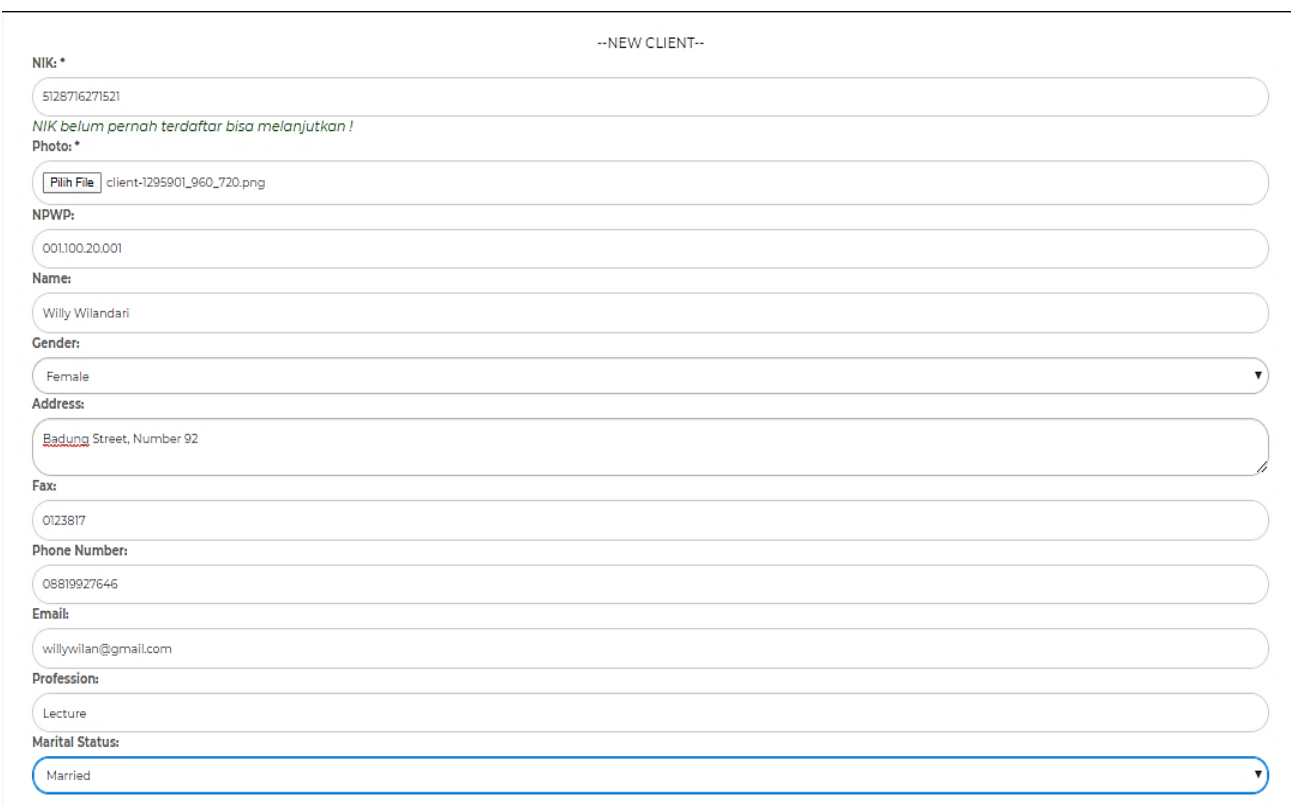

Figure 6. Input Personal information 
Figure 7 is the third step display, where the third step is the upload stage of the service registration document in accordance with the requirements of the selected service type. The client must complete the upload of the document before all data is submitted. When the data is submitted, the service registration process by the client is complete. The registration data will go directly to the system managed by the admin at the notary's office. Admin will make the process of updating progress when one stage has been completed or fulfilled.

Figure 8 is the progress update page that is managed by admin. Admin will do the progress update process. The progress update page will automatically display the stages that are currently running. Figure $\mathrm{x}$ displays the first stage, namely the stage of checking the completeness of the file according to the client's registration data. Furthermore, the client has the right to update the status, "done", "repair", "progress", and "cancel", if all the required documents are correct then the admin will update the status to "done". Information related to the status update will be automatically sent via the Telegram Bot and SMS client, so clients can easily find out information related to the progress of the file work in progress without the need to come directly to the notary's office.

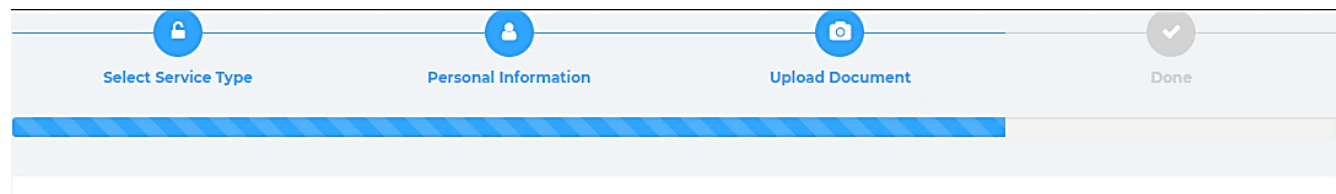

\section{Upload Document:}

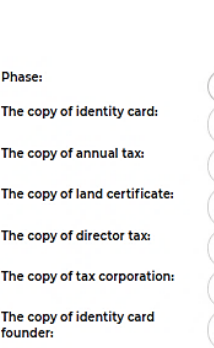

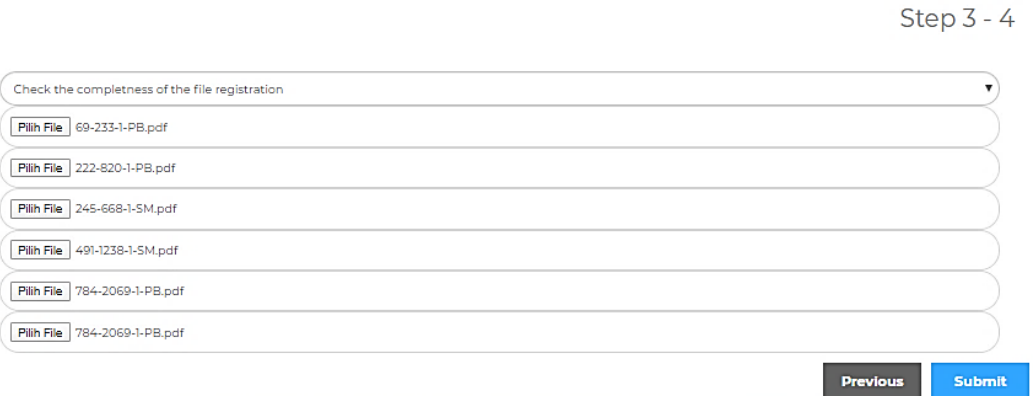

Figure 7. Upload document

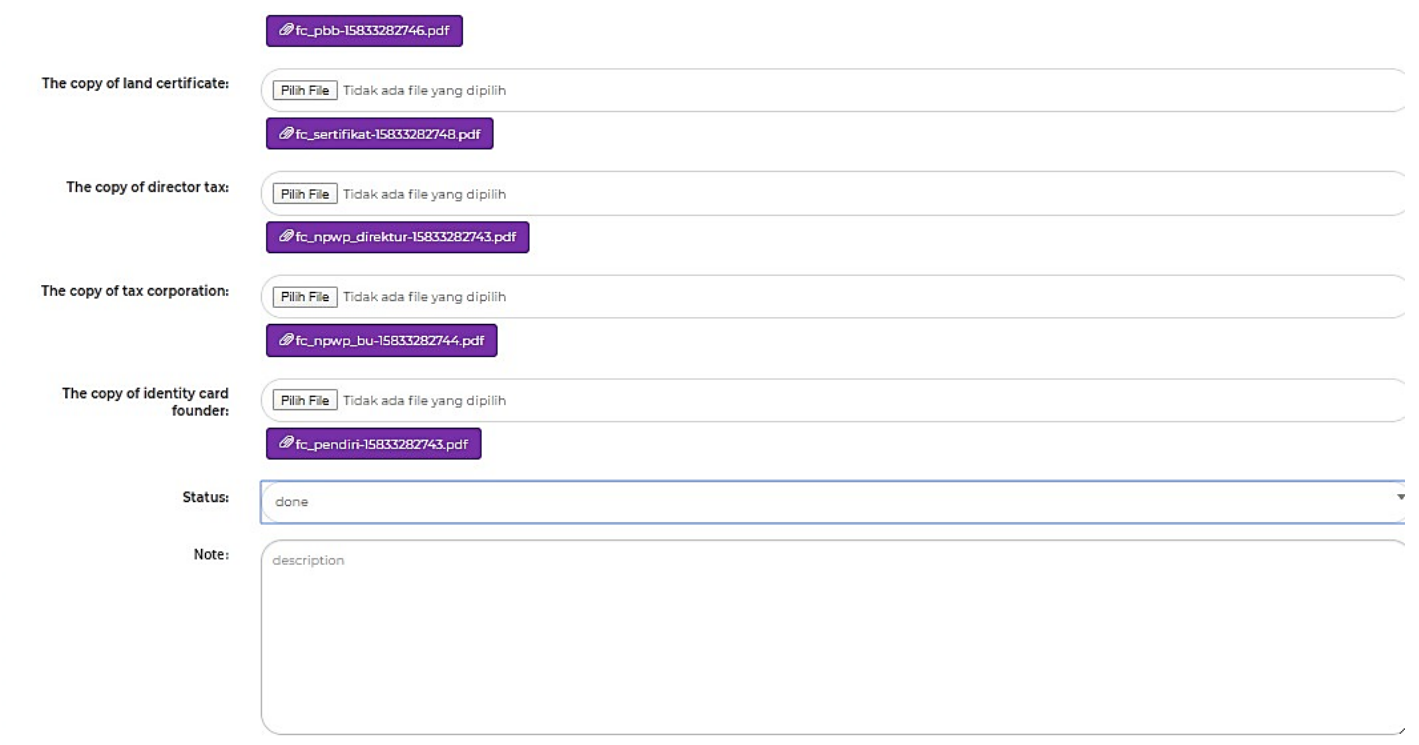

Figure 8. Update progress 


\subsection{Telegram and SMS Bots trials}

Bots are computer programs created specifically to do a job automatically [20]. Bots are run by the application. The commands that are executed are explained in Table 4.

Table 4 is a table that displays commands and functions found in Telegram and SMS Bots. Commands consist of / daftar, / list-request, and / status-id-request. Telegram and SMS bots can also send notifications according to progress updates that occur on the system. Notifications sent from Telegram Bots and SMS will be explained in Table 5.

Table 4. Telegram and SMS Bot

\begin{tabular}{cl}
\hline Command & \multicolumn{1}{c}{ Type of function } \\
\hline /register & Register to the notary service administration system \\
/list-services & Retrieve list of services \\
/service-details & Retrieve file status information based on client's service code \\
\hline
\end{tabular}

Table 5. Notification Telegram and SMS

\begin{tabular}{cc}
\hline Notification & Field \\
\hline File Status Notification & service code, service type, phase, last update, and note \\
\hline
\end{tabular}

Table 5 is a table that displays notifications from the Telegram Bot and SMS. File status notification is sent if there is a progress update from the system. This notification informs you of the status of the work file that is running, the information consists of the client's services code, name of service type, status, date of the last update, and notes if needed.

The trial will be conducted starting from registration through the Telegram Bot application. The trial registration through the Telegram Bot application will be explained in Figure 5.

Figure 9 is a display of client registration through the Telegram application. The client will get a message about how to register, retrieve list of services, and retrieve file status information based on the client's services code. Clients who have registered will get a reply in the form of a message as shown in Figure 10. Figure 10 is a display message received by the client when successfully registering through the Telegram application. The telegram id will be directly stored in the client data database. This telegram id is needed to connect between the system and the client's telegram application. Notification of the status of the work file will be sent after an update on the system, the notification display will be explained in Figure 11.

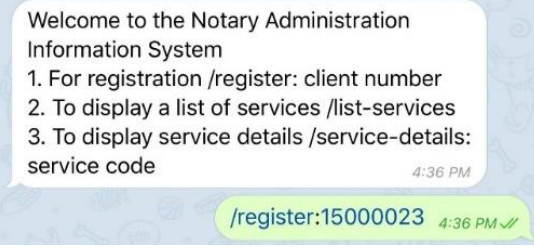

Figure 9. Telegram registrastion
Successfully registered client number $=>$ 15000023 !

Figure 10. Succesfully Register information

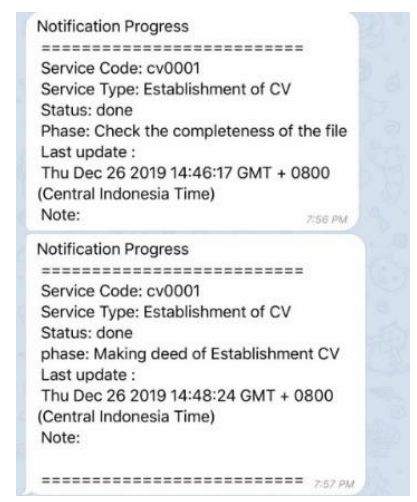

Figure 11. File Status Notification 
Figure 11 is a file status notification display from Bot, a file status notification will be sent to the client when there is an update from the system. The file status notification contains detailed information about the client request, such as the service code, name of service type, status, phase, date of the last update, and notes if needed.

Figure 12 and Figure 13 is the display of file status information when the client sends the message "/service-details: services code. The system will send file status information via Telegram if the client retrieves file status information via Telegram, and via SMS if the client retrieves file status information via SMS. This information contains the service code, the type of service the client selected, the status of whether it was 'done', 'canceled', 'repaired', the phase to indicate what file the current phase was in and the phase that had not yet occured, the last update to display the date and time the last update occurred

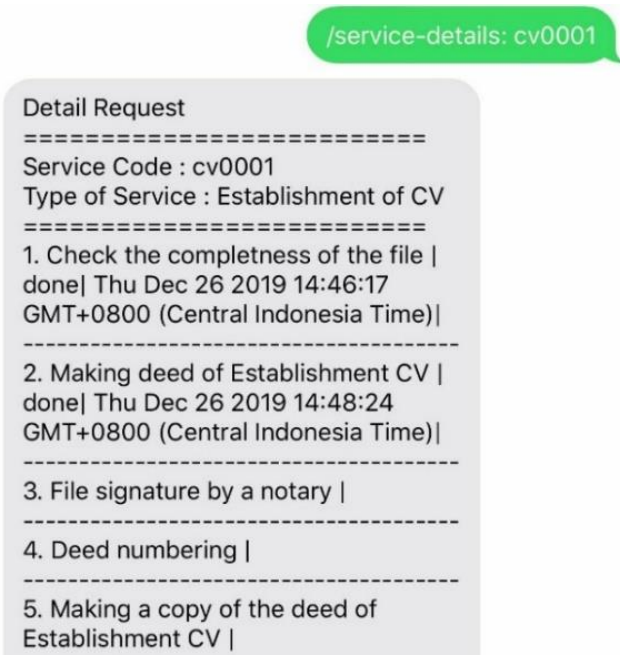

Figure 12. Get Service Details via SMS

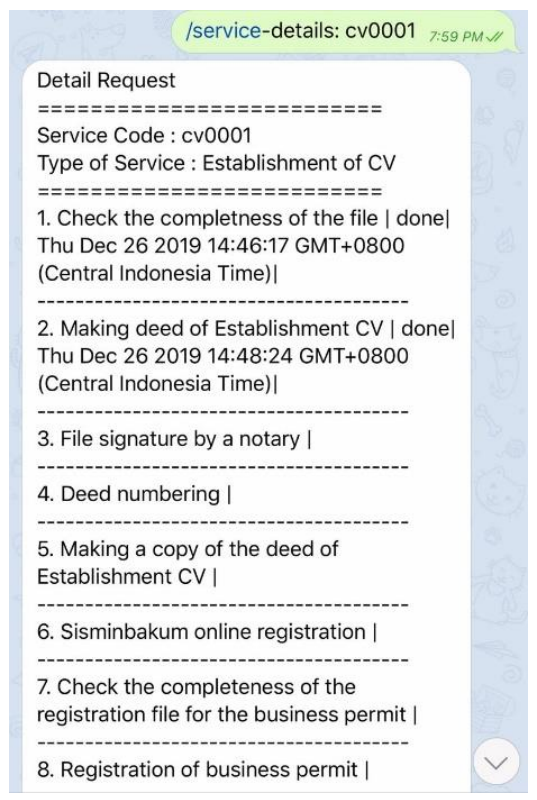

Figure 13. Get Service Details via Telegram

\section{CONCLUSION}

In conclusion, to improve service governance in the notary administration system by implementing the application of Multi Channel Access (MCA) Technology. This system makes it easy for employees to process incoming service files, and makes it easy for employees to provide information to clients through an integrated system with Telegram and SMS Bots, so that the delivery of information is more efficient than before. The results of testing with black box testing have run as expected, while the test results of Likert scale analysis by distributing questionnaires to notary office employees indicate an average index of $96 \%$ of respondents included in the category of strongly agree The application of notary administration system based on Multi Access Access Technology has been tested in a real environment, and has successfully facilitated clients who want to submit requests to the notary public.

\section{REFERENCES}

[1] M. B. Chaniago and A. Junaidi, "Student presence using RFID and telegram messenger application : A study in SMK Unggulan Terpadu Pgii Bandung, Indonesia," International Journal of Higher Education, vol. 8, no. 3, pp. 94-102, 2019.

[2] M. C. S. Vera and B. E. V Comendador, "A web-based student support services system integrating short message service application programming interface," International Journal of Future Computer and Communication, vol. 5, no. 2, 2016.

[3] O. O. O and O. Ogaba, "Result alert system through SMS and E-mail," IOSR Journal of Mobile Computing \& Application, vol. 2, no. 2, pp. 41-45, 2015.

[4] R. Lumaug G, "SENT SMS: School event notification through SMS," Asia Pacific Journal of Multidisciplinary Research, vol. 4, no. 4, pp. 61-68, 2016. 
[5] E. Williams and O. Uzochukwu C, "Electronic file monitoring system," Global Journal Of Pure And Applied Sciences, vol. Vol.21, no. 2010, pp. 71-79, 2015.

[6] K. T. Alemu and T. A. Alemu, "SMS-based agricultural information system for rural farmers in Ethiopia," Journal of Usability Studies, vol. 15, no. 1, pp. 47-62, 2020.

[7] F. Sari and P. Lidya, "Mobile application reminder of SPP payment Schedule ' S A ND School activities information based SMS gateway," Journal of Telecommunication, Electronic and Computer Engineering, vol. 9, no. 3, pp. 27-31, 2017.

[8] Masterjon, "Street light monitoring application based on SMS gateway," International Journal of Scientific and Research Publications, vol. 6, no. 11, pp. 536-539, 2016.

[9] K. Arun and M. G. Nayagam, "Building applications with social networking API's," Int. J. Advanced Networking and Applications, vol. 2075, pp. 2070-2075, 2014.

[10] K. Darmaastawan, et al., "LINE messenger as a transport layer to distribute messages to partner instant messaging," I.J. Modern Education and Computer Science, no. March, pp. 1-9, 2019.

[11] R. C. Dinatha, I. M. Sukarsa, and A. A. K. Agung Cahyawan, "Data exchange service using google drive API," International Journal of Computer Applications, vol. 154, no. 7, pp. 12-16, 2016.

[12] A. Y. Egwoh and O. F. Nonyelum, "A software system development life cycle model for improved students communication and collaboration," International Journal of Computer Science \& Engineering Survey, vol. 8, no. 4, pp. 1-10, 2017.

[13] A. M. Dima and M. A. Maassen, "From waterfall to Agile software: Development models in the IT sector , 2006 to 2018. Impacts on company management," Journal of International Studies, vol. 11, no. 2 , pp. $315-325,2018$.

[14] M. Elamin and E. Daleel, "Software engineering development and analysis of life cycle models," International Journal of Computer Applications, vol. 133, no. 10, pp. 9-13, 2016.

[15] M. H. S. Al, "Importance of data flow diagrams and entity relationships diagrams to data structures systems design in $\mathrm{C}++$ " a practical example ," Journal of Management and Strategy, vol. 8, no. 4, pp. 51-61, 2017.

[16] S. N. Pardeshi, "Study of testing strategies and available tools," International Journal of Scientific and Research Publications, vol. 3, no. 3, pp. 1-4, 2013.

[17] D. A. R, Hustinawaty, I. Jatnika, and H. Medyawati, "Boundary value analysis testing on augmented reality of Indonesian fruit recognition at mekarsari tourist park using cloud method on android mobile devices boundary value analysis testing on augmented reality of Indonesian fruit recognition at mekarsari T," Journal of Physics, vol. 9, no. 1, 2019.

[18] A. Joshi, S. Kale, S. Chandel, and D. K. Pal, "Likert scale : Explored and explained," British Journal of Applied Science \& Technology, vol. 7, no. 4, pp. 396-403, 2015.

[19] T. Sutikno, L. Handayani, D. Stiawan, M. A. Riyadi, and I. M. I. Subroto, "WhatsApp, viber and telegram: Which is the best for instant messaging?," International Journal of Electrical and Computer Engineering (IJECE), vol. 6, no. 3, pp. 909-914, 2016.

[20] P. K. Bala, M. Kumar, S. Hulawale, and S. Pandita, "Chat-bot for college management system using A.I," International Research Journal of Engineering and Technology, vol. 4, no. 11, 2018. 